\title{
Research on a Strategy of Improving Students' Satisfaction with Teaching: An Empirical Study Based on Undergraduate Universities in Sichuan
}

\author{
Anshou Yao $\mathbb{D}^{1},{ }^{1}$ Junhua $W u,{ }^{2}$ and Yongpan Yang ${ }^{3}$ \\ ${ }^{1}$ Academic Affairs Office, Panzhihua University, China \\ ${ }^{2}$ Law School, Panzhihua University, China \\ ${ }^{3}$ Economics and Management School, Panzhihua University, China \\ Correspondence should be addressed to Anshou Yao; yaoanshou@pzhu.edu.cn
}

Received 3 November 2021; Revised 8 December 2021; Accepted 15 December 2021; Published 21 January 2022

Academic Editor: B. B. Gupta

Copyright ( 2022 Anshou Yao et al. This is an open access article distributed under the Creative Commons Attribution License, which permits unrestricted use, distribution, and reproduction in any medium, provided the original work is properly cited.

\begin{abstract}
Objective. To understand the impact of platform selection on each influencing factor of students' teaching evaluation. Method. The factor analysis method was used to analyze the questionnaire survey of students' satisfaction with teaching evaluation in 16 undergraduate colleges and universities in Sichuan Province. The impact of five key factors on students' satisfaction with teaching, i.e., teachers' teaching ethics, teaching ability, teaching content, teaching method, and teaching effect, was explored. Results. It shows that platform selection has a significant impact on various factors in the whole online teaching process. Regarding the degree of impact of platform selection on students' teaching evaluation satisfaction, senior students are slightly higher than junior students, boys are slightly higher than girls, and students majoring in science and technology are slightly higher than those in other disciplines. Conclusion. Due to the great influence of teaching platform selection on online teaching satisfaction, teachers must choose an appropriate teaching platform according to teaching needs.
\end{abstract}

\section{Introduction}

With the rapid development of the network era, the Internet has changed people's life to a great extent, its influence extending all walks of life in the world. According to a survey conducted by Seagate and IDC, the global data quantity is predicted to increase from $16 \mathrm{ZB}$ in 2016 to $163 \mathrm{ZB}$ ( $1 \mathrm{ZB}=1$ billion $\mathrm{TB}=1$ Trillion $\mathrm{GB}$ ) by 2025 , which is equivalent to viewing the Netflix catalogue for 489 million times [1] thanks to the considerable contribution of online teaching. Online teaching, since its advent, has demonstrated a robust development momentum. During the COVID-19 outbreak, in particular, colleges and universities worldwide have been trying online teaching in place of conventional classroom teaching, bringing in a sustained boom of online education.

Conventional teaching is centered on teachers, and their standardized teaching plans pay little attention to individual differences. As teachers base their preparing, teaching, and evaluating work on the majority, the foundation and prog- ress of an individual student cannot be targeted and timely evaluated, with no regard to students' feelings. Many students hold a herd mentality and seldom ask questions, so they are not duly motivated [2]. As the conventional teaching is shifting to the Internet-based mobile learning, students are able to learn anywhere anytime thanks to online teaching. Teachers can also track students' learning status in real time. Teaching evaluation is not standardized anymore. So when teaching platforms are identified, we are expected to consider how to fully present quality teaching contents and integrate students' individuality into platform-based teaching design and evaluation to bring more vitality to teaching and learning [3].

This paper, in the context of the COVID-19 pandemic outbreak, is based on a questionnaire survey of college students' satisfaction with online teaching conducted in some colleges and universities in Sichuan, China. Through the factor analysis, we have investigated factors contributing to students' satisfaction with teaching supported by different online teaching platforms, in an attempt to provide some 
implications and recommendations to deepen teaching reform, improve online teaching quality, and better teaching quality assurance.

\section{Literature Review}

2.1. Online Teaching. From the perspective of teaching design, given that students and teachers online stay spatially apart, we are expected to have purposeful course design for the whole process. An advanced teaching design needs to have the holistic perspective of building a "teacher-guided and student-centered" framework, giving full play to teachers' rich experiences and knowledge and considering appeals and demands of students as the main participants [4]. In terms of teaching media, online teaching is supported by the Internet. With the help of cyber platforms, students can learn anywhere anytime, breaking the limitation of time and space on education. For those job holders who are busy with their assignments and cannot arrange a regular schedule, online distance teaching (i.e., online teaching) is quite convenient and appealing [5]. Thanks to less limitation in time and space, human and material resources can be utilized to the maximum. Students can choose at will when and where to learn. Student-teacher communication and students' autonomous learning are adopted alternatively. Teachers can improve their individualized teaching design and apply innovative teaching tools, namely, the Internet to automatic online teaching management-these features and advantages represent a revolution in teaching driven by technology in the process of learning [6].

2.2. Online Teaching Satisfaction Evaluation. Teaching evaluation refers to evaluating the teaching contents, methods, and attitude of a teacher [7]. An essential component of teaching surveying is how to conduct students' teaching evaluation. Nevertheless, no unified criteria have been formulated, due to factors such as earlier courses' teaching quality, coordination among various teaching links of the course, teacher's performance, and students' foundation and learning attitude. Conventional teaching advocates that teaching evaluation is meant to help improve teaching quality. Therefore, teachers have to formulate a scientific indicator system and criteria based on the teaching objectives, apply effective techniques and methods to search and collect teaching and learning information in a systematic and comprehensive manner, use all feasible evaluation methods and techniques to judge the values of the teaching processes and expected outcomes based on scientific analysis and information processing, and measure the whole process and outcomes of teacher-student interaction, so as to make value judgement and evaluation [8].

In the final analysis, online education evaluation cannot disobey the above principles. We also need to evaluate teachers' teaching ethics, teaching ability, teaching contents, teaching methods, and teaching outcomes, with consideration given to new teaching forms, i.e., modern network technology-supported teaching that transfers conventional classroom teaching onto cyber carriers. Students and the teacher can have teaching and learning interactions sup-

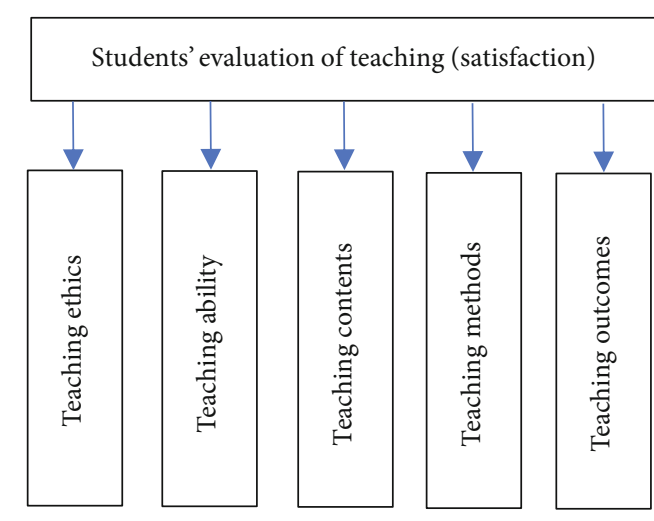

FIGURE 1

ported by smart devices like notebook computers and mobile phones. Therefore, we need to observe the whole process assessment of conventional teaching evaluation and choose suitable equipment and application package. In this regard, online education is much more complicated and requires a systematic and detailed teaching evaluation framework [9]. The impact of different online teaching platforms on students' satisfaction with teaching is comprehensively evaluated from the aspects of teaching ethics, teaching ability, teaching contents, teaching methods, and teaching outcomes (Figure 1).

\section{Students' Evaluation of Teaching: Satisfaction Analysis}

3.1. Evaluation System. Having surveyed relevant literature on online platform selection's impact on students' evaluation of teaching (satisfaction) and some empirical studies on online teaching of colleges and universities in Sichuan, this paper divides the system of students' evaluation of teaching into five level 2 indicators-teacher's teaching ethics, teaching ability, teaching contents, teaching methods, and teaching outcomes. These five parameters are employed to measure students' satisfaction with teaching. Among them, teacher's teaching ethics [10] is made up of four level 3 indicators-political standing, teaching dedication, care for students, and sincerity and amicability. The evaluation of teaching ability [11] involves five level 3 indicators- $\mathrm{Pu}-$ tonghua teaching, mental outlook, logic speaking, specialized knowledge, and scientific research. Teaching contents [12] are measured by five level 3 indicators-teaching arrangement, useful information, theory and practice combination, updated specialized knowledge integration into lessons, and exercise and homework assignment. Teaching methods [13] are measured by four level 3 indicators-rational teaching tools (teaching platforms), class interaction and guidance, effective class supervision, and distinctive teaching features. Teaching outcomes [14] are measured according to five level 3 indicators-ideological and political progress, systematic mastery of course contents, comprehensive specialized knowledge system, improvement in practice and self-development, and teacher's adaption to online teaching. See Table 1 for details. 
TABLE 1: Indicator variables.

\begin{tabular}{|c|c|c|}
\hline Level 1 indicator & Level 2 indicators & Level 3 indicators (measured) \\
\hline \multirow{23}{*}{ Students' evaluation of teaching (satisfaction) } & \multirow{4}{*}{ Teaching ethics } & Q1: political standing \\
\hline & & Q2: teaching dedication \\
\hline & & Q3: care for students \\
\hline & & Q4: sincerity and amicability \\
\hline & \multirow{5}{*}{ Teaching ability } & Q5: Putonghua teaching \\
\hline & & Q6: mental outlook \\
\hline & & Q7: logic speaking \\
\hline & & Q8: specialized knowledge \\
\hline & & Q9: scientific research \\
\hline & \multirow{5}{*}{ Teaching contents } & Q10: teaching arrangement \\
\hline & & Q11: useful information \\
\hline & & Q12: theory and practice combination \\
\hline & & Q13: updated specialized knowledge integration into class \\
\hline & & Q14: exercise and homework assignment \\
\hline & \multirow{4}{*}{ Teaching methods } & Q15: rational teaching tools (teaching platforms) \\
\hline & & Q16: class interaction and guidance \\
\hline & & Q17: effective class supervision \\
\hline & & Q18: distinctive teaching features \\
\hline & \multirow{5}{*}{ Teaching outcomes } & Q19: ideological and political progress \\
\hline & & Q20: systematic mastery of course contents \\
\hline & & Q21: comprehensive specialized knowledge system \\
\hline & & Q22: improvement in practice and self-development \\
\hline & & Q23: teacher's adaption to online teaching \\
\hline
\end{tabular}

TABLE 2: Statistics of samples' basic information.

\begin{tabular}{|c|c|c|c|}
\hline Variable name & Variable options & Variable data & Proportion (\%) \\
\hline \multirow{2}{*}{ Gender } & Male & 2599 & 56.1 \\
\hline & Female & 2818 & 43.9 \\
\hline \multirow{3}{*}{ Grade } & Sophomore & 2556 & 46.1 \\
\hline & Junior & 2633 & 41.0 \\
\hline & Senior & 828 & 12.9 \\
\hline \multirow{6}{*}{ Specialty } & Science \& engineering & 2889 & 45.0 \\
\hline & Economics \& management & 1549 & 24.1 \\
\hline & Literature, history, \& philosophy & 1278 & 19.9 \\
\hline & Agriculture \& medical science & 228 & 3.6 \\
\hline & Law & 81 & 1.3 \\
\hline & Others & 392 & 6.1 \\
\hline
\end{tabular}

3.2. Data Collection. To conduct this survey, 16 colleges and universities in Sichuan that offer four categories-researchoriented undergraduate colleges, research-oriented and teaching-centered undergraduate colleges, teachingcentered and research-involved undergraduate colleges, and teaching-based undergraduate colleges-were identified to survey among 7,846 students specializing in science and engineering; economics and management; agriculture and medical science; literature, history, and philosophy; law; art; and education disciplines. Ultimately, 6,417 valid ques- tionnaires were collected, accounting for $81.79 \%$ of the total number. For a specific question, the Likert scale method was employed to measure students' satisfaction in a five-point scale. The respondents were asked to choose and tick their own choice from "very satisfied," "satisfied," "not sure," "not satisfied," and "very unsatisfied," which are, respectively, assigned with scores of 1 5 points, so as to survey their actual responses for evaluation [15].

The random sampling method and the snowball sampling method were employed to survey the variables of 
gender, grade, and specialty. In general, there are more male respondents than females, accounting for 56.1\%. Most respondents surveyed are college sophomores, accounting for $46.1 \%$. The interviewees mainly specialize in science and engineering, accounting for $45 \%$. The basic information statistics of the samples are shown in Table 2.

\section{Data Analysis}

4.1. Descriptive Statistics. The SPSS20 software has been employed to conduct frequency analysis of the 23 level 3 indicators, which are all between 3 and 4, and their standard deviation is relatively small. The above data apparently show that the majority of respondents are "satisfied" with or "not sure" about online teaching. Analyzing the level 3 indicators, we find that all variables have 1 and 5 , respectively, for the minimum and maximum values. Surveying the mean values of the 23 level 3 indicators, we find that "teaching tools (teaching platforms)" has the lowest satisfaction with the mean value of 3.3. After the weighted average processing of level 3 indicators, we find that the level 2 indicator "teaching method" has relatively low satisfaction, with a mean value of 3.528. Other level 3 indicators are all above 3.3, and all level 2 indicators are above 3.5. Apparently, colleges and universities should call attention to the indicator of "teaching tools (platforms)" in particular. Detailed statistics of the variables are shown in Table 3.

4.2. Reliability Test. To ensure all indicators in the questionnaire are reliable, we have used Cronbach's $\alpha$ coefficient $\left(\alpha=(k /(k-1)) *\left(1-\left(\sum \mathrm{Si} 2\right) / \mathrm{St} 2\right)\right)$ to measure the reliability of indicators related to students' satisfaction. Suppose higher $\alpha$ coefficient represents higher reliability, so we assume that samples with a $\alpha$ value higher than 0.6 are taken as acceptable, and the assumed optimal sample $\alpha$ value is above 0.8 [16]. Statistics of level 1 and level 2 indicators' reliability (see Table 4) show that the reliability coefficient value for the level 1 indicators is 0.887 , higher than 0.8 . This means that level 1 indicators are in the scope of optimum application. The reliability coefficient values for the level 2 indicators are, respectively, 0.746, 0.797, 0.713, 0.646, and 0.689, all above 0.6. This indicates that level 2 indicators are in the scope of normal application.

4.3. Factor Analysis. To further determine the factors used to measure students' satisfaction, we have employed factor analysis to extract the main factors for students' evaluation to reconstruct a teaching evaluation indicator system. With the help of the KMO test, we have conducted a validity test of the partial correlation among various factors for students' teaching evaluation and found that the KMO value of this data set is 0.916 , which is between 0.8 and 1.0. We have also conducted Bartlett's test for the data. The result shows that the approx. chi-square value is 70646.062 , and the corresponding significance value is near 0 , which is close to 0.05 . So the relevant coefficient and its corresponding data are remarkably different. Based on the KMO and Bartlett's test results, we can determine that it is appropriate to carry
TABLE 3: Statistics of variables.

\begin{tabular}{lccccc}
\hline $\begin{array}{l}\text { Measured } \\
\text { variables }\end{array}$ & $\begin{array}{c}\text { Total } \\
\text { samples }\end{array}$ & Minimum & Maximum & $\begin{array}{c}\text { Mean } \\
\text { value }\end{array}$ & $\begin{array}{c}\text { Standard } \\
\text { deviation }\end{array}$ \\
\hline Q1 & 6417 & 1 & 5 & 3.66 & 1.199 \\
Q2 & 6417 & 1 & 5 & 3.58 & 1.183 \\
Q3 & 6417 & 1 & 5 & 3.6 & 1.147 \\
Q4 & 6417 & 1 & 5 & 3.51 & 1.173 \\
Q5 & 6417 & 1 & 5 & 3.57 & 1.144 \\
Q6 & 6417 & 1 & 5 & 3.77 & 1.157 \\
Q7 & 6417 & 1 & 5 & 3.56 & 1.118 \\
Q8 & 6417 & 1 & 5 & 3.33 & 1.186 \\
Q9 & 6417 & 1 & 5 & 3.32 & 1.181 \\
Q10 & 6417 & 1 & 5 & 3.34 & 1.177 \\
Q11 & 6417 & 1 & 5 & 3.64 & 1.109 \\
Q12 & 6417 & 1 & 5 & 3.43 & 1.137 \\
Q13 & 6417 & 1 & 5 & 3.71 & 1.115 \\
Q14 & 6417 & 1 & 5 & 3.59 & 1.084 \\
Q15 & 6417 & 1 & 5 & 3.3 & 1.089 \\
Q16 & 6417 & 1 & 5 & 3.6 & 1.087 \\
Q17 & 6417 & 1 & 5 & 3.56 & 1.109 \\
Q18 & 6417 & 1 & 5 & 3.36 & 1.099 \\
Q19 & 6417 & 1 & 5 & 3.37 & 1.087 \\
Q20 & 6417 & 1 & 5 & 3.68 & 1.052 \\
Q21 & 6417 & 1 & 5 & 3.61 & 1.073 \\
Q22 & 6417 & 1 & 5 & 3.62 & 1.075 \\
Q23 & 6417 & 1 & 5 & 3.57 & 1.098 \\
\hline & & & & & \\
\hline
\end{tabular}

TABLE 4: Reliability analysis.

\begin{tabular}{lccc}
\hline Indicators & $\begin{array}{c}\text { Cronbach's } \\
\text { alpha value }\end{array}$ & Indicators & $\begin{array}{c}\text { Cronbach's } \\
\text { alpha value }\end{array}$ \\
\hline $\begin{array}{l}\text { Teaching ethics } \\
\text { Teaching ability }\end{array}$ & 0.746 & Teaching methods & 0.646 \\
$\begin{array}{l}\text { Teaching } \\
\text { contents }\end{array}$ & 0.797 & $\begin{array}{c}\text { Teaching outcomes } \\
\text { Students' overall } \\
\text { satisfaction }\end{array}$ & 0.689 \\
\hline
\end{tabular}

TABLE 5: KMO and Bartlett's tests.

\begin{tabular}{lcc}
\hline $\begin{array}{l}\text { Sufficient sampling for Kaiser-Meyer-Olkin } \\
\text { measurement }\end{array}$ & 0.916 \\
& Approx. chi-square & 70646.062 \\
Bartlett's test & Degrees of freedom & 253 \\
& Significance & 0.000 \\
\hline
\end{tabular}

out factor analysis [17]. Relevant data test results are shown in Table 5.

Common factor variance is employed to indicate the communality among variables, which shows the representation of common factors extracted from original information contained in various variables, so it is an important indicator for measuring the effect of factor analysis. The measurement 
TABLE 6: Variable common factor variance.

\begin{tabular}{|c|c|c|c|c|c|}
\hline Variable & Initial value & $\begin{array}{c}\text { Extracted } \\
\text { value }\end{array}$ & Variable & Initial value & $\begin{array}{c}\text { Extracted } \\
\text { value }\end{array}$ \\
\hline Putonghua teaching & 1 & 0.732 & Updated specialized knowledge integration into class & 1 & 0.621 \\
\hline Handwriting & 1 & 0.751 & Exercise and homework assignment & 1 & 0.737 \\
\hline Clear \& logic speaking & 1 & 0.718 & Teaching tools (teaching platforms) & 1 & 0.522 \\
\hline Specialized knowledge & 1 & 0.582 & Interaction and guidance & 1 & 0.673 \\
\hline Scientific research & 1 & 0.556 & Effective class supervision & 1 & 0.714 \\
\hline Political standing & 1 & 0.600 & Distinctive teaching features & 1 & 0.633 \\
\hline Teaching dedication & 1 & 0.639 & Ideological \& political progress & 1 & 0.578 \\
\hline Care for students & 1 & 0.704 & Systematic mastery of course contents & 1 & 0.705 \\
\hline Sincerity \& amicability & 1 & 0.753 & Comprehensive specialized knowledge system & 1 & 0.673 \\
\hline Teaching arrangement & 1 & 0.549 & Improvement in practice and self-development & 1 & 0.577 \\
\hline Useful information & 1 & 0.659 & Teacher's adaption to online teaching & 1 & 0.522 \\
\hline Theory and practice combination & 1 & 0.691 & & & \\
\hline
\end{tabular}

TABLE 7: Total variances explained.

\begin{tabular}{lcccccc}
\hline Component & & 1 & 2 & 3 & 4 & \\
\hline \multirow{2}{*}{ Initial eigenvalue } & Total & 7.258 & 3.048 & 2.063 & 1.128 & 1.092 \\
& Variance (\%) & 31.556 & 13.253 & 8.968 & 4.904 & 4.749 \\
& Accumulation (\%) & 31.556 & 44.809 & 53.776 & 58.680 & 63.429 \\
\hline \multirow{2}{*}{ Extraction sums of squared loadings } & Total & 7.258 & 3.048 & 2.063 & 1.128 & 1.092 \\
& Variance (\%) & 31.556 & 13.253 & 8.968 & 4.904 & 4.749 \\
& Accumulation (\%) & 31.556 & 44.809 & 53.776 & 58.680 & 63.429 \\
\hline \multirow{2}{*}{ Rotation sums of squared loadings } & Total & 4.315 & 3.611 & 2.421 & 2.254 & 1.988 \\
& Variance (\%) & 18.761 & 15.700 & 10.525 & 9.799 & 8.644 \\
& Accumulation (\%) & 18.761 & 34.461 & 44.985 & 54.785 & 63.429 \\
\hline
\end{tabular}

variable's common factor variance is shown in Table 6 . Statistics in the table show that the extracted value for each factor is higher than 0.5 , and their communality is within the normal scope. This means that the extracted communality can reflect the relevant information of the original indicator variables.

Principal component analysis-based solution for factor loadings readily shows that the first principal component has an eigenvalue of 7.258 , whose total variance explained is $31.556 \%$. The first three components' eigenvalues are all above 2, but their accumulative contribution is only $53.776 \%$, while the first four principal components only have $58.68 \%$ total variance explained. Suppose the standard accumulative contribution for principal components extraction is $60 \% \sim 70 \%$ : when the fifth component is added, the accumulative variance contribution can reach $63.429 \%$, so we have five principal components in this paper. The details are shown in Table 7.

The maximum variance method of factor analysis has been employed to rotate relevant factors, and the factor load matrix before relevant factor analysis rotation shows that the load values for F1 and F3 are below 0.5. The values are relatively small, which means the two factors bear no explicit implications and cannot be clearly explained. Thus, factor rotation is employed to have further specified the reflection of various dimensions. The rotated factor load matrix is shown in Table 8 . As can be seen from the matrix, F1 and F5 have quite high load values in teaching contents and teaching methods, respectively, among which the load value in teaching tools (teaching platforms) is as high as 0.907 . Thus, we may conclude that F1 reflects students' satisfaction mainly in terms of teaching contents and teaching methods, which have the biggest impact on teaching tools (teaching platforms). F2 and F3 show relatively high load values in teaching ethics and teaching ability, respectively, whose values are between 0.511 and 0.848 , all of which are higher than 0.5 . Thus, we can conclude that they represent students' satisfaction with teacher's teaching ethics and teaching ability, respectively.

Based on the mean value of the above five satisfaction indicators of students from 16 colleges and universities in Sichuan, we can obtain a ranking of students' teaching satisfaction evaluation. This ranking shows that different students have quite different satisfaction with online teaching regarding teacher's teaching ethics, teaching ability, teaching contents, teaching methods, and teaching outcomes, especially in terms of teaching tools (teaching platforms). Thus, colleges can overcome their own shortcomings by learning from others' strong points in this respect, so as to achieve a higher overall teaching satisfaction. 
TABLE 8: Rotated factor load matrix.

\begin{tabular}{|c|c|c|c|c|c|c|}
\hline \multirow{2}{*}{ Level 2 indicators } & \multirow{2}{*}{ Level 3 indicators } & \multicolumn{5}{|c|}{ Components } \\
\hline & & F1 & F2 & F3 & F4 & F5 \\
\hline \multirow{4}{*}{ Teaching ethics } & Political standing & 0.092 & 0.848 & 0.039 & 0.007 & 0.173 \\
\hline & Teaching dedication & 0.359 & 0.777 & 0.011 & 0.129 & 0.070 \\
\hline & Care for students & 0.069 & 0.722 & 0.005 & 0.167 & 0.387 \\
\hline & Sincerity \& amicability & 0.051 & 0.511 & 0.229 & 0.228 & 0.208 \\
\hline \multirow{5}{*}{ Teaching ability } & Putonghua teaching & 0.022 & 0.098 & 0.722 & 0.007 & 0.340 \\
\hline & Handwriting & 0.062 & 0.001 & 0.742 & 0.131 & 0.211 \\
\hline & Clear \& logic speaking & 0.052 & 0.015 & 0.796 & 0.006 & 0.007 \\
\hline & Specialized knowledge & 0.167 & 0.067 & 0.543 & 0.593 & 0.183 \\
\hline & Scientific research & 0.425 & 0.017 & 0.741 & 0.111 & 0.011 \\
\hline \multirow{5}{*}{ Teaching contents } & Teaching arrangement & 0.041 & 0.300 & 0.097 & 0.364 & 0.626 \\
\hline & Useful information & 0.207 & 0.088 & 0.062 & 0.004 & 0.805 \\
\hline & Theory and practice combination & 0.135 & 0.116 & 0.391 & 0.257 & 0.671 \\
\hline & Updated specialized knowledge integrated into class & 0.039 & 0.477 & 0.060 & 0.054 & 0.598 \\
\hline & Exercise and homework assignment & 0.185 & 0.104 & 0.024 & 0.008 & 0.851 \\
\hline \multirow{4}{*}{ Teaching methods } & Teaching tools (teaching platforms) & 0.907 & 0.022 & 0.071 & 0.119 & 0.021 \\
\hline & Class interaction and guidance & 0.679 & 0.027 & 0.031 & 0.414 & 0.206 \\
\hline & Effective class supervision & 0.832 & 0.141 & 0.009 & 0.039 & 0.220 \\
\hline & Distinctive teaching features & 0.742 & 0.079 & 0.142 & 0.043 & 0.379 \\
\hline \multirow{5}{*}{ Teaching outcomes } & Ideological and political progress & 0.219 & 0.304 & 0.341 & 0.558 & 0.015 \\
\hline & Systematic mastery of course contents & 0.030 & 0.108 & 0.012 & 0.832 & 0.204 \\
\hline & Comprehensive specialized knowledge system & 0.134 & 0.389 & 0.019 & 0.706 & 0.027 \\
\hline & Improvement in practice and self-development & 0.328 & 0.010 & 0.061 & 0.610 & 0.434 \\
\hline & Teacher's adaption to online teaching & 0.364 & 0.085 & 0.072 & 0.533 & 0.460 \\
\hline
\end{tabular}

\section{Online Teaching Platform's Impact on Students' Overall Satisfaction with Teaching}

5.1. Variation Analysis. Variance analysis [18] is employed to analyze students' satisfaction with different online platforms. From the result of the variation analysis, we can learn that students of different grades and specialties show no significant difference in their satisfaction with teacher's teaching ethics. However, a certain significant difference can be found in students' satisfaction with teaching ethics based on students' gender, teaching ability based on grade, teaching contents based on specialty, and teaching outcomes based on grade and specialty. Additionally, a larger significant difference is noted in students' satisfaction with teaching ability based on gender and specialty, teaching contents based on specialty, teaching methods based on grade, and teaching outcomes based on gender. The difference in students' satisfaction with teaching contents based on gender and teaching methods based on gender and specialty is the most significant. The details are shown in Table 9. This variance analysis shows that the results lie in several aspects. On the one hand, students' satisfaction with teaching platforms is mainly attributed to students' mastery of teaching contents and teachers' teaching methods. On the other hand, students' satisfaction with teaching platforms directly impacts whether the teaching contents and methods can be
TABLE 9: Variation analysis of teaching platforms.

\begin{tabular}{lccccc}
\hline $\begin{array}{l}\text { Students' } \\
\text { satisfaction with } \\
\text { teaching }\end{array}$ & F1 & F2 & F3 & F4 & F5 \\
\hline Grade & 0.065 & $0.036^{*}$ & $0.039^{*}$ & $0.030^{* *}$ & $0.042^{*}$ \\
Gender & $0.023^{*}$ & $0.013^{* *}$ & $0.014^{* * *}$ & $0.011^{* * *}$ & $0.015^{* *}$ \\
Specialty & 0.060 & $0.034^{* *}$ & $0.036^{* *}$ & $0.007^{* * *}$ & $0.036^{*}$ \\
\hline
\end{tabular}

presented to the maximum extent during their teaching process. Therefore, students' satisfaction with teaching is also dependent on their satisfaction with teaching methods and contents.

5.2. Empirical Analysis. To know online teaching platforms' impact on contributors to students' satisfaction with teaching more clearly, we build a multiple linear regression model [19], whose computational formula is $y=\beta 0+\beta 1 \times 1+\beta 2$ $\times 2+\cdots+\beta n \times n+\S$. For modeling and data analysis, the explained variable is students' satisfaction with teaching, with the satisfaction with teaching ethics (F1), teaching ability (F2), teaching contents (F3), teaching methods (F4), and teaching outcomes (F5) being the proxy variables. The selection of online teaching platforms is the major explanatory variable; the impacts of age, gender, specialty, and teaching 
TABLE 10: Regression analysis.

\begin{tabular}{lccccc}
\hline Students' satisfaction with teaching & F1 & F2 & Components & F3 & F4 \\
\hline Grade & $0.016(12.995)$ & $0.016(1.185)$ & $0.015^{*}(1.718)$ & $0.013^{* * *}(0.327)$ & $0.079^{* *}(12.299)$ \\
\hline Gender & $0.020^{*}(3.972)$ & $0.013(0.546)$ & $0.014^{*}(1.590)$ & $0.021^{* *}(1.795)$ & $0.032(16.282)$ \\
\hline Specialty & $0.005^{*}(20.731)$ & $0.012^{* *}(3.738)$ & $0.008^{* *}(15.765)$ & $0.024^{* *}(3.624)$ & $0.049(2.047)$ \\
\hline Teaching platform & $0.004^{*}(0.257)$ & $0.028^{*}(1.464)$ & $0.021^{* * *}(1.319)$ & $0.125^{* * *}(7.616)$ & $0.174^{* * *}(12.387)$ \\
\hline Regular variables & $0.076^{*}(33.191)$ & $0.954^{* *}(11.679)$ & $0.970^{*}(12.299)$ & $0.957^{* *}(11.459)$ & $0.892^{* *}(10.403)$ \\
\hline$N$ & 6417 & 6417 & 6417 & 6417 & 6417 \\
\hline$R^{2}$ & 0.432 & 0.496 & 0.702 & 0.856 & 0.536 \\
\hline
\end{tabular}

N.B.: (1) $*, * *$, and $* * *$ refer to $1 \%, 5 \%$, and $10 \%$ statistical significance, respectively. (2) Numbers in brackets represent the $T$ values.

platform on students' satisfaction with teaching are all incorporated into the multiple linear regression model as dummy variables. Based on the above formula, we obtain the results in Table 10, which indicates that teaching platforms have a direct impact on students' satisfaction with teaching. Thus, different platforms have significantly different impacts on students' satisfaction with teaching. This conclusion is further analyzed and explained from the five dimensions of students' satisfaction with teaching.

As can be seen from the regression analysis, gender, specialty, and teaching platform play significant roles in the students' satisfaction with teaching ethics. Specifically, male students' satisfaction is slightly higher than that of female students, students specializing in science and engineering are the most satisfied, and the satisfaction with teaching platforms is averaged 3.37, which belongs to the moderate level. This means that male students' requirements for teaching ethics are lower than those of female students. Specialty has a relatively significant impact on students' satisfaction with teaching, while teaching platforms not only have an impact on students' satisfaction with teaching methods but also contribute most to their overall satisfaction with teaching.

In terms of students' satisfaction with teaching ability, the regression analysis shows that only specialty plays a relatively significant role, with certain impact being given to teaching platforms. Considering that students with science and engineering backgrounds show slightly higher significance than students with other specialty backgrounds and different platforms are interconnected, this indicates that students' satisfaction with teaching ability impacts their satisfaction with teaching platforms and is one of the main indicators that affects their satisfaction with teaching.

As for students' satisfaction with teaching contents, all factors in the regression analysis have certain significant impact on this dimension, among which teaching platforms play a major significant role. This indicates that teaching platforms and their ability to get the teaching contents well presented are the leading contributors to students' satisfaction with teaching contents.

In regard to students' satisfaction with teaching methods, the regression analysis shows that this dimension is similar to students' satisfaction with teaching contents, and their difference mainly lies in grades. Students at higher grades have slightly higher satisfaction than lower graders. This demonstrates that teaching platforms do play a major role in students' satisfaction with teaching methods and that teachers need to present high-level teaching methods apart from selecting suitable teaching platforms.

With regard to students' satisfaction with teaching outcomes, the regression analysis shows that both grades and teaching platforms have significant impact, among which teaching platforms plays the most significant role. This suggests that students' satisfaction with teaching not only significantly relies on grades but also highly depends on teaching platforms.

In conclusion, the regression analysis of the five dimensions of students' satisfaction with teaching shows that teaching platforms play a significant role during the whole process of online teaching. Only with a suitable teaching platform can a teacher deliver a satisfactory online teaching experience.

\section{Conclusion and Recommendations}

This paper carries out a questionnaire survey of students' satisfaction with online teaching among students from 16 colleges and universities in Sichuan. To conduct the factor analysis, we studied students' satisfaction from five dimensions-teaching ethics, teaching ability, teaching contents, teaching methods, and teaching outcomes. The multiple linear regression model is adopted to analyze the key contributors to students' satisfaction. According to our results, the following recommendations are proposed to improve students' satisfaction with teaching using proper teaching platforms.

As the teaching mastery, ability, contents, and methods vary from teacher to teacher, students' satisfaction also differs, which will be somehow dependent on teaching platforms. In other words, students' satisfaction with teaching platforms can positively regulate the overall satisfaction with teaching. The regulative intensity, however, changes along with the different indicators of students' satisfaction. Among them, teaching ethics has not been significantly affected, teaching ability, contents, and methods are influenced 
significantly, and teaching effect is mostly impacted. Therefore, while choosing a teaching platform, colleges and universities should emphasize teaching mastery, ability, and contents, as well as the ultimate outcomes. For different teaching contents, correspondingly suitable platforms should be chosen, so as to enhance students' satisfaction with teaching to the greatest extent.

\section{Data Availability}

The data used to support the findings of this study are included within the article.

\section{Conflicts of Interest}

The authors declare that they have no competing interest.

\section{Acknowledgments}

This paper is supported by the Project on Talent Cultivation Quality and Teaching Reform of Higher Education in Sichuan Province for 2018-2020: "Exploration and Practice of Student-centered Local Application-oriented Undergraduate Talents Training Quality Assurance System" (JG2018-841).

\section{References}

[1] GS Education, Global Education Sector Report: Prediction, GSV Education Consultancy Co., Ltd, US, 2017.

[2] H. Yong, "Online education in China: evolution and status quo," in Talents Cultivation and Teaching Reform, pp. 197201, Collected Papers for Teaching Reform of Zhejiang Gongshang University, 2015.

[3] V. Phelps, Successful Online Learning with Gifted Students: Designing Online and Blended Lessons for Gifted and Advanced Learners in Grades 5-8, Taylor and Francis, 2021.

[4] B. Yuan, Live Class-Centered Online Teaching: Concept and Practice, no. article 02023, 2020Tencent, 2020, https://new.qq .com/omn/20200223/20200223A06WSZ00.

[5] V. Mkrttchian, D. Kharicheva, E. Aleshina et al., "Avatarbased learning and teaching as a concept of new perspectives in online education in post-Soviet Union countries," International Journal of Virtual and Personal Learning Environments, vol. 10, no. 2, pp. 66-82, 2020.

[6] Y. He and A. Ma, "Practice and discussion on online teaching of university PE during the period for prevention and control of COVID-19," International Journal of Education and Economics, vol. 3, no. 2, pp. 24-28, 2020.

[7] R. Hughes, L. Dahlin, and T. Tucci, "An investigation of a multiple-measures teaching evaluation system and its relationship with students' college-going outcomes," Educational Policy, vol. 35, no. 1, pp. 131-158, 2021.

[8] T. Zhang, "Building quality assurance system for applicationoriented universities from the perspective of education evaluation," Education and Career, vol. 18, pp. 52-54, 2019.

[9] J. Lee, T. Sanders, D. Antczak et al., "Influences on user engagement in online professional learning: a narrative synthesis and meta-analysis," Review of Educational Research, vol. 91, no. 4, pp. 518-576, 2021.
[10] Z. Jiang, C. Zhao, H. Li, Y. Liang, and Y. Huang, "Research on online open course learners satisfaction: development, contributors and improvement prospect," Modern Long-Distance Education, vol. 3, pp. 34-43, 2017.

[11] B. Yang, “Teachers' capability indicators converging development cultivation model building-teacher's professional development in the context of "Internet + " new media," $E$ Education Research, vol. 41, no. 6, pp. 105-112, 2020.

[12] X. Wang and J. Wang, "Substantial equivalence: bottom line objectives for online teaching during the pandemic outbreak," E-Education Research, vol. 42, no. 3, pp. 42-47, 2020.

[13] Z. Liu, "A successful surfing: reflections on contingency online teaching," China Higher Education Research, vol. 4, no. 4, pp. 7-11, 2020

[14] L. Zhao and Y. Zhao, "Online teaching outcome evaluation and quality assurance system building," Research in Higher Education of Engineering, vol. 2, no. 2, pp. 189-194, 2021.

[15] Q. Zhou and H. Chen, "Mental disposition law and application of questionnaire survey respondents," Statistics \& DecisionMaking, vol. 3, no. 3, pp. 34-38, 2018.

[16] Z. Liu and Z. Liu, "Cronbach a coefficient-oriented questionnaire design strategies," Contemporary Education Research and Teaching Practice, vol. 4, no. 4, pp. 173-174, 2016.

[17] L. Wang, X. Tang, and F. Wang, "Factor analysis of contributors to private car ownership in all provinces of China," Economic Outlook the Bohaisea, vol. 4, no. 4, pp. 167-168, 2019.

[18] Q. Liao, G. Lei, D. Zhang, and S. Patil, "Estimation of macrodispersivity in bounded formations by circulant embedding and analysis of variance," Water Resources Research, vol. 57, no. 7, article e2020WR029358, 2021.

[19] C. Xiaojun and J. Fuxing, "Customer relationship management, internal control and merger and acquisition performance-analysis of multivariate linear regression model," Management Review, vol. 33, no. 8, pp. 256-262, 2021. 